\title{
BMJ Open Alcohol consumption behaviours in the immediate aftermath of earthquakes: time series study
}

Daiki Kobayashi, ${ }^{1}$ Hana Hayashi, ${ }^{2}$ Hironori Kuga, ${ }^{3}$ Nagato Kuriyama, ${ }^{4}$ Yoshihiro Terasawa, ${ }^{5}$ Yasuhiro Osugi, ${ }^{5}$ Osamu Takahashi, ${ }^{1}$ Gautam Deshpande, ${ }^{6}$ Ichiro Kawachi ${ }^{7}$

To cite: Kobayashi D, Hayashi $\mathrm{H}$, Kuga $\mathrm{H}$, et al. Alcohol consumption behaviours in the immediate aftermath of earthquakes: time series study. BMJ Open 2019;9:e026268. doi:10.1136/ bmjopen-2018-026268

- Prepublication history for this paper is available online. To view these files, please visit the journal online (http://dx.doi. org/10.1136/bmjopen-2018026268).

Received 25 August 2018 Revised 24 January 2019 Accepted 12 February 2019
Check for updates

(C) Author(s) (or their employer(s)) 2019. Re-use permitted under CC BY-NC. No commercial re-use. See rights and permissions. Published by BMJ.

For numbered affiliations see end of article.

Correspondence to Dr Daiki Kobayashi; daikoba@luke.ac.jp

\section{ABSTRACT}

Objectives Earthquakes are a distressing natural phenomenon that can disrupt normal health-related behaviours. The aim of this study was to investigate changes in alcohol consumption behaviours in the immediate aftermath of mild to moderate earthquakes.

Setting This retrospective cohort study was conducted at a large academic hospital in Tokyo, Japan from April 2004 to March 2017.

Participants We included all adult patients presenting with acute alcohol intoxication in the emergency room. Primary and secondary outcome measures Our outcome was the number of such patients per 24 hours period comparing days with and without earthquake activity. We mainly focused on mild to moderate earthquakes (Shindo scale of less than 3 ). We conducted a simple generalised autoregressive conditional heteroscedasticity (GARCH) analysis, followed by a multivariate GARCH, including year-fixed effects and secular changes in alcohol taxation. Subanalyses were conducted by gender and age group.

Results During the study period, 706 earthquakes were observed with a median Shindo scale of 2 (IQR: 1). During this period, 6395 patients were admitted with acute ethanol intoxication; the mean age was 42.6 (SD: 16.9$)$ years and 4592 (71.8\%) patients were male. In univariate analyses, the occurrence of daytime earthquakes was marginally inversely related to the number of acutely intoxicated patients ( $\beta$ coefficient: $-0.19,95 \% \mathrm{Cl}-0.40$ to 0.01$)$. This finding remained similar in multivariate analyses after adjustment for covariates. In analyses stratified by gender, the inverse association between daytime earthquakes and alcohol intoxication was only observed among men $(p<0.03$ for males and $p=0.99$ for females). In subanalyses by age, older people were less likely to be admitted to the hospital due to acute alcohol intoxication on days with daytime earthquakes $(p=0.11)$, but this was not the case for younger people $(p=0.36)$.

Conclusion On days when a mild to moderate daytime earthquake occurred, the number of patients with acute alcohol intoxication was lower compared with days without earthquakes. Even milder forms of potentially catastrophic events appear to influence social behaviour; mild to moderate earthquake activity is associated with the avoidance of excessive alcohol consumption.

\section{Strengths and limitations of this study}

- This unique study is the first to evaluate alcohol consumption behaviour in the immediate aftermath of earthquakes.

- Robust analyses, by sensitivity analyses with three methods in addition to the main analysis by multivariate generalised autoregressive conditional heteroscedasticity approach, supported the findings in this study.

- The limitation of this study was its analysis of a single centre with a single ethnicity.

\section{INTRODUCTION}

Catastrophic earthquake activity has been reported to exert a variety of effects on both physical and mental health. ${ }^{1}$ A previous study reported that approximately $42.6 \%$ of victims exhibited moderate to serious mental health problems after the Great East Japan earthquake, which occurred in March 2011. ${ }^{1}$ Acute health effects associated with earthquake activity include acute stress disorders, ${ }^{2}$ delirium $^{3}$ and acute and transient psychotic disorders. Long-term effects on victims' wellbeing have also been reported, including post-traumatic stress disorder and exacerbation of bipolar disorder. ${ }^{4-6}$ Although most previous research has been limited to the health impacts of rare catastrophic earthquakes, very few studies have focused on the health effects associated with substantially more common mild to moderate earthquakes.

Substance abuse is a common disorder reported in the setting of catastrophic disasters. ${ }^{78}$ Several studies have explored this relationship with regard to alcohol use behaviours, ${ }^{9} 10$ with several previous studies reporting an increased prevalence of alcohol abuse after major earthquakes. ${ }^{11} 12$ However, in the larger context of catastrophic phenomena, this association remains unclear, with one report showing only a $2 \%$ increase 
in prevalence after a major hurricane ${ }^{13}$ and other studies reporting a slight decrease in alcohol abuse after instances of terrorism. ${ }^{914}$ Moreover, some suggested that disasters have rarely increased the prevalence of substance use disorders. Instead, increased alcohol abuse after disaster can often reflect an exacerbation of existing abuse rather than new-onset disorders. ${ }^{15}$ As such, the effect of disasters on alcohol abuse remains controversial. Previous studies have suggested that gender, age, education and even cultural background modify these associations. ${ }^{16} 17$

Japan is a tectonically active country where earthquakes are observed frequently. The Japan Meteorological Agency observed 2025 earthquakes in 2017, and more than 6500 earthquakes were observed in 2016 in Japan. ${ }^{18}$ Among the 76 earthquakes in 2017 and 123 events in $2016,3.8 \%$ and $1.9 \%$, respectively, were greater than a magnitude of 5. In addition to the incidence of earthquakes, the Japan Meteorological Agency recorded the date, time, magnitude, location and seismic intensity. ${ }^{19}$ Thus, the aim of this study was to evaluate the same-day association between mild to moderate earthquakes and unhealthy alcohol use behaviour in Japan.

\section{METHODS}

\section{Study design and cohort description}

We conducted a retrospective daily time series study using medical record data from St. Luke's International Hospital in Tokyo, Japan from April 2004 to March 2017. We included all patients who were 20 years or older and presented to the hospital emergency room (ER) with acute alcohol intoxication. We excluded all patients who signed opt-out agreements for their anonymised data to be used in research. In addition, patients presenting with an altered mental status of uncertain origin were excluded. Our outcome was a patient volume of acutely intoxicated patients per 24 hours period. Outcomes were compared between days with and without earthquakes, as observed by the Japan Meteorological Agency.

\section{Patient and public involvement}

There was no involvement of patients other than this data and the public.

\section{Acute alcohol intoxication}

Emergency physicians at the hospital clinically diagnosed with acute alcohol intoxication based on testimonies by patients or their companions. A blood ethanol level of $100 \mathrm{mg} / \mathrm{dL}$ or higher was used to support the diagnosis for those whose testimonies could not be elicited directly. ${ }^{20}$

\section{Earthquake}

All earthquake data were obtained from the Japan Meteorological Agency. ${ }^{18}$ The recorded data contain the time and date of occurrence, the Richter magnitude, the depth of epicentre and Shindo scale data for any earthquake detected. With a range of $0-7$, Shindo is the unique measurement scale used in Japan for seismic intensities in a specific area. ${ }^{19}$ Unlike the Richter scale, which represents the size of the earthquake itself and is unique for each earthquake, Shindo scaling reflects the intensity of the observed shaking in a given area and is based on the distance from the epicentre at which the seismic activity was observed. Generally speaking, the further the observed area is from the epicentre, the lower the Shindo measurement is for that area. A Shindo score of 1 is comparable to mild shaking observed only when sitting quietly in a structure, while a Shindo score of 4 is defined as observable shaking that is intense enough to startle, awaken people from sleep and can be detected while walking. A Shindo score of 7 equates to severe shaking in which it is impossible to remain standing or move without crawling. In terms of the severity of the earthquake, we defined earthquakes with a Shindo score of 1-3 as mild to moderate earthquakes and those with a Shindo score of 4 or more as severe earthquakes. We defined a daytime earthquake as one observed between 09:00 and 17:00, while a night-time earthquake was defined as occurring between 17:00 and mid-night. The reason why we divided earthquakes as above is that a daytime earthquake was believed to affect the subsequent drinking behaviour on the same night. In contrast, a night-time earthquake that may have occurred while drinking alcohol was believed to have a different effect on drinking behaviour. The remaining time period, from 00:00 to 09:00, was considered as having little effect on alcohol behaviour.

\section{Study site}

St. Luke's International Hospital is located in Chuoku, Tokyo, Japan. The hospital, a 520-bed tertiary-level community teaching hospital, accepts more than 10000 ambulance admissions per year. Located close to Ginza, a major entertainment district popular for bars and restaurants serving alcohol, St. Luke's receives the largest number of ambulances per year, including approximately $50 \%$ of ambulances dispatched from the Ginza area. We included only earthquakes that were observed in this metropolitan Tokyo area in the analyses.

Category of the day in relation to work week and seasonality Because the incidence of acute alcohol intoxication is considered to vary substantially by the day of the week, we divided the days into three categories: weekdays, days prior to a non-working day and non-working days (generally understood in Japan to be Saturday, Sunday and designated national holidays). For days overlapping categories, we considered days prior to a non-working day the most dominant. For instance, because December 31st, January 1st, 2nd and 3rd are designated national holidays in Japan, we categorised December 31st, January 1st and 2nd as 'days prior to a non-working day', and 3rd as a 'non-working day'.

As the incidence of acute alcohol intoxication is also considered to be related to seasonality, we categorised March, April and May as spring; June, July and August 


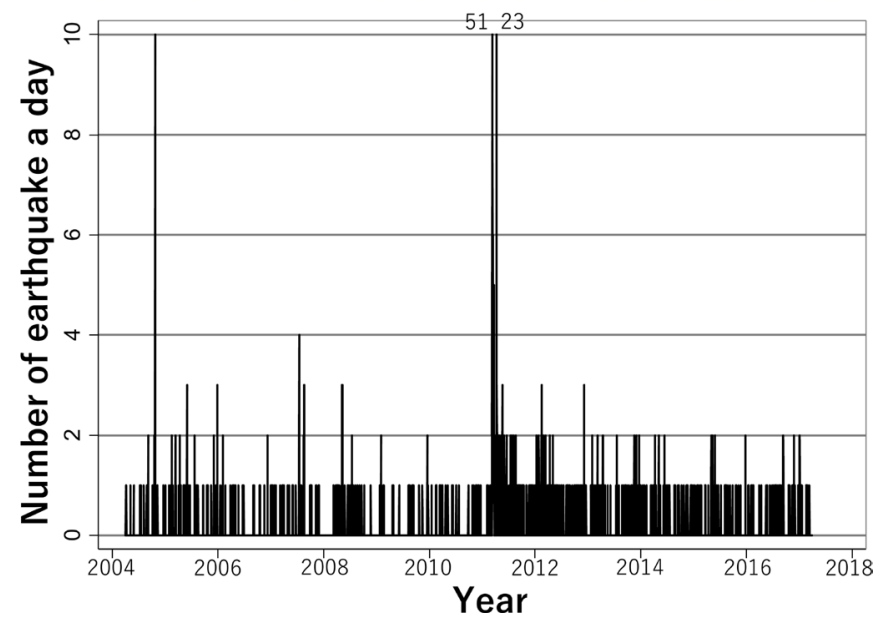

Figure 1 The number of earthquakes per day.

as summer; September, October and November as fall; December, January and February as winter.

\section{Statistical analyses}

Because the occurrence of earthquakes on a certain day was considered to be autocorrelated and have an autoregressive conditional heteroscedasticity effect (figure 1), we applied a multivariate generalised autoregressive conditional heteroscedasticity (GARCH) approach with dynamic conditional correlation to investigate the association between patients' presentation in the ER and acute alcohol intoxication and occurrence of earthquakes. ${ }^{21-23}$ In terms of the primary outcome, we first applied a simple GARCH model with each variable examining the relationship between hospital admission for acute alcohol intoxication and earthquake activity, the category of day and seasonality. This was followed by a multivariate GARCH $(1,1)$ model with variables found to have a $p$ value of 0.2 or lower in the simple GARCH model, as well as a year-fixed effect and changes in alcohol taxation. Alcohol taxation had changed five times during study periods, and it is included the model as a categorical variable. Because the taxation rates were similar during the study periods (eg, $45.1 \%-46.6 \%$ for beer, $16.2 \%-18.1 \%$ for sake), the impact of alcohol taxation change on the results was considered to be limited. The $\beta$ coefficient and $95 \%$ CIs were calculated. In addition, we stratified the analyses by both gender and age (50 years or older vs less than 50 years). Moreover, we separately analysed data before the Great East Japan earthquake on 11 March 2011 and after the earthquake. We also conducted sensitivity analyses to check robustness with the following three methods: using the Richter scale magnitude as a covariate to evaluate whether the results differ according to the magnitude of the earthquake; introducing different lag times between the earthquake and hospital visits (eg, 1, 3 or 7 days after the earthquakes), excluding days in which severe earthquakes (Shindo scale $\geq 4$ ) occurred and having the data stratified by day of the week. All analyses were performed using Stata V.14.0 (Stata Corp, TX, USA).
Table 1 Patients' characteristics

Patients $(\mathrm{n}=6395)$

\begin{tabular}{lc}
\hline Age, year, mean (SD) & $42.6(16.9)$ \\
\hline Male, $\mathrm{n}(\%)$ & $4592(71.8)$ \\
\hline Blood alcohol level, mg/dL, mean (SD) & $225.4(87.2)$ \\
\hline Type of day when the patient visited the hospital \\
Weekdays, $\mathrm{n}(\%)$ & $3125(48.9)$ \\
\hline Days prior to day off, $\mathrm{n}(\%)$ & $1220(19.1)$ \\
\hline Day off, $\mathrm{n}(\%)$ & $2050(32.1)$
\end{tabular}

Season in which the patient visited the hospital

$\begin{array}{ll}\text { Spring, } \mathrm{n}(\%) & 1562(24.4) \\ \text { Summer, } \mathrm{n}(\%) & 1558(24.4) \\ \text { Fall, } \mathrm{n}(\%) & 1617(25.3) \\ \text { Winter, n (\%) } & 1658(25.9)\end{array}$

The occurrence of earthquake when the patient visited the hospital

$\begin{array}{ll}\text { A whole day, } \mathrm{n}(\%) & 657(10.3) \\ \text { Daytime earthquake, } \mathrm{n}(\%) & 197(3.1) \\ \text { Night-time earthquake, } \mathrm{n}(\%) & 188(2.94)\end{array}$

\section{RESULTS}

During the study period, earthquakes were observed 706 times with a median Shindo score in the catchment area of 2 (IQR: 1). During the 4747 days in the study period, earthquakes were observed on 500 days. During this period, 6571 patients were extracted from the electronic medical record. Among them, 99 were excluded because they were younger than 20 years old, and 77 were excluded based on the blood alcohol level. Finally, 6395 patients with a mean age of 42.6 (SD: 16.9) were treated for acute ethanol intoxication; 4592 (71.8\%) were male (table 1).

Table 2 shows the results for the number of patients with acute ethanol intoxication from the simple and multivariate GRACH models. In univariate analyses, the daytime earthquake figure was marginally and inversely related to the number of acutely intoxicated patients $(\beta$ coefficient: $-0.19,95 \%$ CI -0.40 to 0.01$)$. The number of days prior to a non-working day ( $\beta$ coefficient: 0.26 , $95 \%$ CI 0.15 to 0.37 ) was significantly related and the number of non-working days ( $\beta$ coefficient: $0.08,95 \%$ CI -0.01 to 0.14 ) was marginally significantly related to acute intoxication. These findings remained similar in multivariate analyses after adjusting for both occurrences of a daytime earthquake, the category of day, seasonality, yearfixed effect and change in alcohol taxation. In a sensitivity analysis, including Richter scale magnitude as a covariate to evaluate whether the results differ according to the magnitude of the earthquake, the daytime earthquake number was still marginally related to decreased patient volume ( $\beta$ coefficient: $-0.23,95 \%$ CI -0.47 to 0.01 ). However, the magnitude of the earthquake itself had 
Table $2 \beta$ coefficients for the number of patients with acute ethanol intoxication from the univariate and multivariate GARCH model

\begin{tabular}{|c|c|c|c|c|c|c|}
\hline \multirow[b]{2}{*}{ Variable } & \multicolumn{3}{|c|}{ Univariate $\mathrm{GARCH}^{\star}$ model } & \multicolumn{3}{|c|}{ Multivariate GARCH ${ }^{\star}$ model } \\
\hline & $\beta$ coefficient & $95 \% \mathrm{Cl}$ & $P$ value & $\beta$ coefficient & $95 \% \mathrm{Cl}$ & $P$ value \\
\hline \multicolumn{7}{|l|}{ Earthquake factors } \\
\hline Incidence of earthquake & 0.00 & $(-0.12$ to 0.12$)$ & 0.95 & & & \\
\hline $\begin{array}{l}\text { Number of earthquakes a day, } \\
\text { times }\end{array}$ & -0.02 & $(-0.06$ to 0.03$)$ & 0.46 & & & \\
\hline The depth of the epicentre, $\mathrm{km}$ & 0.00 & $(-0.01$ to 0.01$)$ & 0.85 & & & \\
\hline The highest magnitude in a day & 0.00 & $(-0.02$ to 0.02$)$ & 0.98 & & & \\
\hline The highest Shindo in a day & 0.00 & $(-0.08$ to 0.07$)$ & 0.92 & & & \\
\hline Daytime earthquake $\dagger$ & -0.19 & $(-0.40$ to 0.01$)$ & 0.06 & -0.18 & $(-0.38$ to 0.02$)$ & 0.07 \\
\hline Night-time earthquake $\neq$ & 0.12 & $(-0.12$ to 0.35$)$ & 0.34 & & & \\
\hline \multicolumn{7}{|l|}{ Date } \\
\hline \multicolumn{7}{|l|}{ Categories of day } \\
\hline Weekday & Reference & & & Reference & & \\
\hline The day before non-working day & 0.26 & $(0.15$ to 0.37$)$ & $<0.01$ & 0.25 & $(0.15$ to 0.36$)$ & $<0.01$ \\
\hline Non-working day & 0.08 & $(-0.01$ to 0.17$)$ & 0.05 & 0.08 & $(-0.01$ to 0.16$)$ & 0.08 \\
\hline \multicolumn{7}{|l|}{ Season } \\
\hline Spring & Reference & & & Reference & & \\
\hline Summer & 0.02 & $(-0.09$ to 0.13$)$ & 0.73 & 0.02 & $(-0.09$ to 0.12$)$ & 0.78 \\
\hline Fall & 0.05 & $(-0.06$ to 0.17$)$ & 0.35 & 0.03 & $(-0.76$ to 0.14$)$ & 0.55 \\
\hline Winter & 0.10 & (-0.01 to 0.22$)$ & 0.07 & 0.12 & (0.02 to 0.23 ) & 0.02 \\
\hline
\end{tabular}

Numbers in bold indicate that the $p$ value is less than 0.05 .

${ }^{*} \mathrm{GARCH}$, generalised autoregressive conditional heteroscedasticity. The multivariate GARCH model was adjusted for variables found to have a p value of 0.2 or less in a simple GARCH model as well as year-fixed effect and changes in alcohol taxation.

†Daytime earthquake means that an earthquake was observed between 09:00 and 17:00.

$\ddagger$ Night-time earthquake means that earthquake was observed between 17:00 and mid-night.

no relationship with patient volume ( $\beta$ coefficient: 0.01 , $95 \% \mathrm{CI}-0.02$ to 0.04$)$. When we introduced different lag times between the earthquake and hospital visits, the number of daytime earthquakes was also marginally significantly related to decreased patient volume ( $\beta$ coefficient: $-0.18,95 \%$ CI -0.38 to 0.01 for 1 day after an earthquake; $\beta$ coefficient: $-0.18,95 \%$ CI -0.38 to 0.02 for 3 days after an earthquake; and $\beta$ coefficient: -0.18 , $95 \%$ CI -0.38 to 0.02 for 7 days after an earthquake), while different lag times themselves were not associated with patient volume. When we excluded days in which severe earthquakes (Shindo scale $\geq 4$ ) occurred, the findings were similar [daytime earthquake ( $\beta$ coefficient: $-0.18,95 \% \mathrm{CI}-0.38$ to 0.02$)]$. In the analyses by stratification of day of the week, the number of daytime earthquakes was not related to patient volume on weekdays ( $\beta$ coefficient: $0.01,95 \%$ CI -0.28 to 0.30 ) but tend to be negatively related to patient volume on days off ( $\beta$ coefficient: $-0.15,95 \%$ CI -0.49 to 0.19$)$. The analysis was not concaved in the days prior to days off.

Table 3 shows the result of the number of patients with alcohol intoxication from univariate and multivariate analyses stratified by gender. The inverse association between daytime earthquake and alcohol intoxication seen in a pooled analysis was only observed among men ( $p<0.03$ for males and $\mathrm{p}=0.99$ for females). Although $\mathrm{a}$ positive association between the day before non-working days and acute alcohol intoxication were observed in both males $(\mathrm{p}<0.01)$ and females $(\mathrm{p}<0.01)$, higher rates of intoxication on non-working days were only observed in women ( $\mathrm{p}=0.02$ for females and $\mathrm{p}=0.35$ for males). Among male patients, the number of patients with acute alcohol intoxication rose in the winter compared with spring $(\mathrm{p}=0.01)$, but not among females $(\mathrm{p}=0.42)$.

Table 4 shows the result for the number of patients with alcohol intoxication from univariate and multivariate analyses stratified by age group. Older people were less likely to be admitted to the ER due to acute alcohol intoxication on days when daytime earthquakes occurred $(p=0.11)$, but the same pattern was not seen among younger people $(p=0.36)$. Both older and younger patients with acute alcohol intoxication were more likely to be admitted on days before non-working days as well as on non-working days compared with weekdays. However, in terms of seasonality, older people were significantly more likely to be admitted to the ER with acute alcohol intoxication in the winter $(\mathrm{p}<0.01)$, but not younger people $(p=0.83)$. In terms of stratification by the 


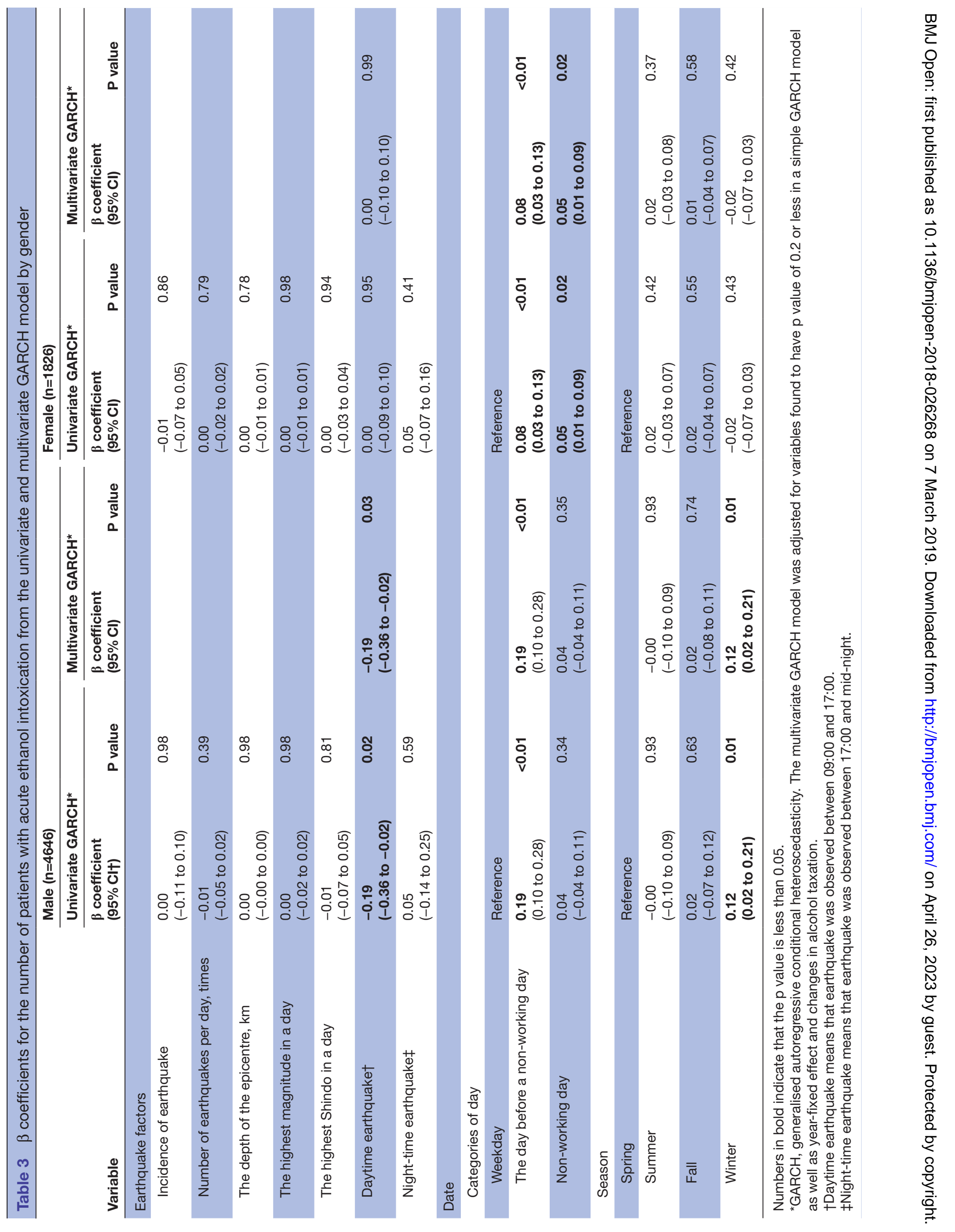




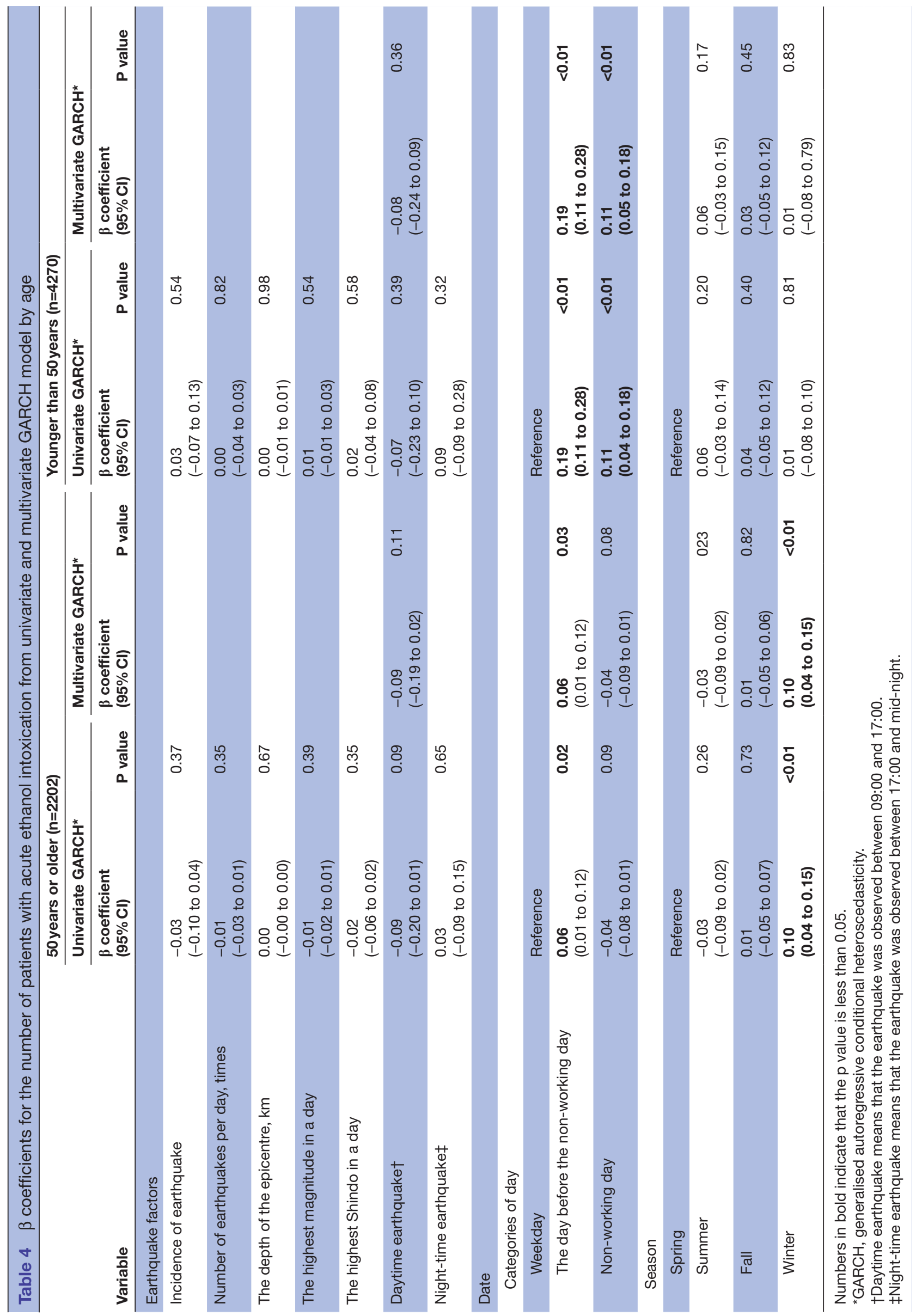

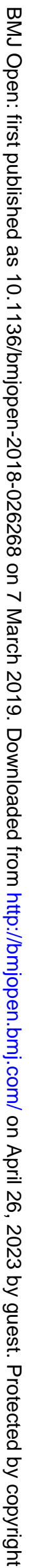


date of the Great East Japan earthquake, the number of daytime earthquakes was inversely related to the number of acutely intoxicated patients after the Great East Japan earthquake ( $\beta$ coefficient: $-0.28,95 \%$ CI -0.55 to -0.02 ), while the number of daytime earthquakes was not related to the number before the Great East Japan earthquake ( $\beta$ coefficient: $-0.02,95 \%$ CI -0.32 to 0.29 ).

\section{DISCUSSION}

Our study found several predictors of the number of intoxicated patients presenting in the ER of a major urban hospital in Japan. Notably, there was an inverse relationship between the number of intoxicated patients and daytime earthquakes observed in older patients and men.

Although previous studies that evaluated drinking behaviour after catastrophic earthquakes reported both positive and negative effects, we found that non-catastrophic earthquakes may exert a dampening (ie, a health-favourable) effect on excess alcohol consumption. This finding was considered to be a type of stress-related growth, which is the theory that people develop from negative events. ${ }^{24}$ We speculate that people may avoid risky behaviours, such as going out with companions after work, to indulge in excessive amounts of drinking immediately after an earthquake. When people experience earthquakes, many may suspect additional tectonic activity; multiple earthquakes in a single day are common and were observed on $83(16.7 \%)$ days in our study. As a result, we suspect that many people choose to go home rather than go out, as has been documented in reports about catastrophic earthquakes. ${ }^{25}$ People may avoid social activities, such as after-work gatherings, on days in which even mild but nevertheless frightening natural phenomena have occurred, thereby reducing the opportunities for excessive drinking and other risky social behaviours. Lower blood alcohol levels noted on earthquake days also suggest that even imbibers may limit the amount of alcohol consumed on such days. Similar social behaviours have been observed after the Great East Japan earthquake in 2011, although whether these behavioural changes are conscious or unconscious remains unclear. ${ }^{26}$

We found both age and gender differences in the relationship between daytime earthquakes and acute alcohol intoxication. There were statistically fewer male patients with acute alcohol intoxication on days when a daytime earthquake occurred compared with days without seismic activity. Interestingly, this relationship was not found for female patients. A previous systematic review reported that differing patterns of alcohol use between men and women are driven by both biological and psycho-socio-cultural factors. ${ }^{27}$ As a result, men are more likely to seek sensations, including hazardous drinking, than women in ordinary settings. ${ }^{28}{ }^{29}$ However, it is possible that mild earthquakes may affect these psycho-socio-cultural factors more for men than women. Social capital may play an important role in this. ${ }^{30}$ Because most Japanese male workers drink with colleagues after work, ${ }^{31}$ some may suggest that others not go out to drink after work on days with earthquakes.

In terms of age, fewer older patients with acute alcohol intoxication were observed on days with earthquakes, despite an unchanged number of younger patients presenting with acute alcohol intoxication on these days. A previous survey about alcohol use reported that younger people tended to indulge in more binge drinking and heavy episodic drinking in Japan ${ }^{32}$ and other countries. ${ }^{33}$ Psychologically disturbing natural phenomena, however mild, may also exert specific inhibitory psycho-socio-cultural effects on risky behaviours of younger people. Further research is needed to evaluate the potential mechanisms for these differences.

Significantly fewer patients with acute alcohol intoxication were observed on days with daytime earthquakes compared with those on days without daytime earthquakes after the Great East Japan earthquake, while the finding was not observed before the Great East Japan earthquake. This suggests that people still have catastrophic earthquakes in mind and avoid sensation seeking from stress-related growth.

Our study has some limitations. First, not all potential patients with acute alcohol intoxication were transferred to our hospital, resulting in a measure of selection bias. However, because our hospital has the largest number and highest rate of ambulance acceptances in Tokyo, with more than $50 \%$ of ambulances dispatched to the local entertainment area were transferred to us, and we assume that this bias is neither large nor differential. In addition, the findings may not be applicable to other countries because ethnicity and cultural diversity could exist. ${ }^{34}$ Second, because we were unable to accurately record information about when patients started to consume alcohol, precise knowledge of the temporal relationship between alcohol consumption, intoxication and earthquakes are difficult to assess. Similarly, because qualitative data concerning patients' physical and emotional perception of seismic activity is not available, further studies are warranted in this area. In addition, evaluation for acute stress disorder may be useful to explain the gender and age difference of findings. Finally, an earthquake itself may somewhat impact hospital operations. However, the emergency department of hospitals had operated as usual on and after the Great East Japan earthquake. Therefore, the impact is considered to be limited.

\section{CONCLUSION}

On days when mild to moderate daytime earthquakes occurred, our hospital had fewer patients with acute alcohol intoxication presenting in the ER. This pattern was also seen for men and elderly patients. Even mild natural phenomena may lead to changes in social behaviour that result in avoidance of excessive alcohol use. 
Author affiliations

${ }^{1}$ Medicine, St. Luke's International Hospital, Tokyo, Japan

${ }^{2}$ McCann Health, McCann Public Health, Tokyo, Japan

${ }^{3}$ Department of Mental Health, Johns Hopkins University Bloomberg School of Public Health, Baltimore, Maryland, USA

${ }^{4}$ Epidemiology for Community Health and Medicine, Kyoto Prefectural University of Medicine, Kyoto, Japan

${ }^{5}$ General Internal Medicine, Fujita Health University, Toyoake, Japan

${ }^{6}$ Medicine, Juntendo University - Hongo Campus, Bunkyo-ku, Japan

${ }^{7}$ Society, Human Development and Health, Harvard School of Public Health, Boston, Massachusetts, USA

Acknowledgements The authors express their sincere thanks to Ms Aya Oizumi and Ms Chika Horikawa for the data extraction.

Contributors DK organised and conducted this study and wrote the whole manuscript. HH, HK, NK, YT, YO and OT contributed to writing the manuscript and made important comments on it. GD and IK contributed to the study design, statistical analyses and discussion.

Funding The authors have not declared a specific grant for this research from any funding agency in the public, commercial or not-for-profit sectors.

Competing interests None declared.

Patient consent for publication Not required.

Ethics approval The ethical committee at St. Luke's International Hospital approved this study (approval number: 17-R025).

Provenance and peer review Not commissioned; externally peer reviewed.

Data sharing statement In terms of data sharing, no additional patient data were available, although data about earthquakes were available on the Japan Meteorological Agency website.

Open access This is an open access article distributed in accordance with the Creative Commons Attribution Non Commercial (CC BY-NC 4.0) license, which permits others to distribute, remix, adapt, build upon this work non-commercially, and license their derivative works on different terms, provided the original work is properly cited, appropriate credit is given, any changes made indicated, and the use is non-commercial. See: http://creativecommons.org/licenses/by-nc/4.0/.

\section{REFERENCES}

1. Yokoyama Y, Otsuka K, Kawakami N, et al. Mental health and related factors after the Great East Japan earthquake and tsunami. PLoS One 2014;9:e102497.

2. Zhou P, Zhang Y, Wei C, et al. Acute stress disorder as a predictor of posttraumatic stress: a longitudinal study of Chinese children exposed to the Lushan earthquake. Psych J 2016;5:206-14.

3. Awata S. [Disaster psychiatry in late life]. Nihon Rinsho 2013;71:1864-9.

4. Navarro-Mateu F, Salmerón D, Vilagut G, et al. Post-Traumatic stress disorder and other mental disorders in the general population after Lorca's earthquakes, 2011 (Murcia, Spain): a cross-sectional study. PLoS One 2017;12:e0179690.

5. Cai D, Zhu Z, Sun H, et al. Maternal PTSD following exposure to the wenchuan earthquake is associated with impaired mental development of children. PLoS One 2017;12:e0168747.

6. Derivois D, Cénat JM, Joseph NE, et al. Prevalence and determinants of post-traumatic stress disorder, anxiety and depression symptoms in street children survivors of the 2010 earthquake in Haiti, four years after. Child Abuse Negl 2017;67:174-81.

7. Seligman J, Felder SS, Robinson ME. Substance Abuse and Mental Health Services Administration (SAMHSA) behavioral health disaster response app. Disaster Med Public Health Prep 2015;9:516-8.

8. Moise IK, Ruiz MO. Hospitalizations for substance abuse disorders before and after hurricane katrina: spatial clustering and arealevel predictors, New Orleans, 2004 and 2008. Prev Chronic Dis 2016;13:E145.

9. North CS, Pfefferbaum B. Mental health response to community disasters: a systematic review. JAMA 2013;310:507-18.
10. Vlahov D, Galea S, Resnick H, et al. Increased use of cigarettes, alcohol, and marijuana among Manhattan, New York, residents after the September 11th terrorist attacks. Am J Epidemiol 2002;155:988-96.

11. Pollice R, Bianchini V, Roncone R, et al. Marked increase in substance use among young people after L'Aquila earthquake. Eur Child Adolesc Psychiatry 2011;20:429-30.

12. Keyes KM, Hatzenbuehler ML, Hasin DS. Stressful life experiences, alcohol consumption, and alcohol use disorders: the epidemiologic evidence for four main types of stressors. Psychopharmacology 2011;218:1-17.

13. David D, Mellman TA, Mendoza LM, et al. Psychiatric morbidity following Hurricane Andrew. J Trauma Stress 1996;9:607-12.

14. Knudsen HK, Roman PM, Johnson JA, et al. A changed America? The effects of September 11th on depressive symptoms and alcohol consumption. J Health Soc Behav 2005;46:260-73.

15. Neria Y, Galea S, Norris FH. Mental Health and Disasters: Cambridge University Press, 2009.

16. Cepeda A, Saint Onge JM, Kaplan C, et al. The association between disaster-related experiences and mental health outcomes among drug using African American Hurricane Katrina evacuees. Community Ment Health J 2010;46:612-20.

17. Bianchini V, Roncone R, Giusti L, et al. PTSD Growth and substance abuse among a College Student Community: Coping Strategies after 2009 L'aquila Earthquake. Clin Pract Epidemiol Ment Health 2015;11:140-3

18. Japan Meteorological Agency. Shindo database. 2018 http://www. jma.go.jp/jma/indexe.html (Accessed 10 Apr 2018).

19. Rückinger S, von Kries R, Toschke AM. An illustration of and programs estimating attributable fractions in large scale surveys considering multiple risk factors. BMC Med Res Methodol 2009;9:7.

20. Vonghia L, Leggio L, Ferrulli A, et al. Acute alcohol intoxication. Eur J Intern Med 2008;19:561-7.

21. Bollerslev T. Generalized autoregressive conditional heteroskedasticity. J Econom 1986;31:307-27.

22. Engle RF. Autoregressive conditional heteroscedasticity with estimates of the variance of United Kingdom Inflation. Econometrica 1982;50:987-1007.

23. Engle R. Dynamic conditional correlation: a simple class of multivariate generalized autoregressive conditional heteroskedasticity models. Journal of Business \& Economic Statistics 2002:20:339-50.

24. Park CL, Cohen LH, Murch RL. Assessment and prediction of stressrelated growth. J Pers 1996;64:71-105.

25. Ito K, Aono A, Ohmori N. Empirical study on stop-offs en route home in the aftermath of an earthquake disaster in the Tokyo Metropolitan area - analyses based on an online questionnaire survey about the Great East Japan Earthquake. Journal of the City Planning Institute of Japan 2013;48(No.3):873-8.

26. Zaré M, Afrouz SG. Crisis management of tohoku; Japan earthquake and tsunami, 11 march 2011. Iran J Public Health 2012;41:12-20.

27. Erol A, Karpyak VM. Sex and gender-related differences in alcohol use and its consequences: contemporary knowledge and future research considerations. Drug Alcohol Depend 2015;156:1-13.

28. Bosque-Prous M, Espelt A, Borrell C, et al. Gender differences in hazardous drinking among middle-aged in Europe: the role of social context and women's empowerment. Eur J Public Health 2015;25:698-705.

29. Holmila M, Raitasalo K. Gender differences in drinking: why do they still exist? Addiction 2005;100:1763-9.

30. Zarzar PM, Jorge KO, Oksanen T, et al. Association between binge drinking, type of friends and gender: a cross-sectional study among Brazilian adolescents. BMC Public Health 2012;12:257.

31. Hagihara A, Tarumi K, Nobutomo K. Work stressors, drinking with colleagues after work, and job satisfaction among white-collar workers in Japan. Subst Use Misuse 2000;35:737-56.

32. Osaki $Y$, Kinjo A, Higuchi S, et al. Prevalence and trends in alcohol dependence and alcohol use disorders in Japanese Adults; Results from Periodical Nationwide Surveys. Alcohol Alcohol 2016;51:465-73.

33. Quinn PD, Harden KP. Differential changes in impulsivity and sensation seeking and the escalation of substance use from adolescence to early adulthood. Dev Psychopathol 2013;25:223-39.

34. Betsy T. Risk-taking behaviour in men Substance use and gender. 2003 https://pdfs.semanticscholar.org/2067/3ca32192d2577058acc9 430f2ae6ad988d31.pdf (Accessed 4 Aug 2018). 